\title{
Using tools to distinguish general and occupation-specific skills
}

\author{
Cindy M. Cunningham ${ }^{1}$ and Robert D. Mohr ${ }^{2 *}$
}

\begin{abstract}
Data on tool use from O*Net's Tools and Technologies Supplement can, in conjunction with task-based measures, provide a new proxy for measuring and distinguishing general and specific skills at the occupational level. The tools and types of tools used in an occupation generate reasonable proxies for skill that vary across occupations and appear to capture features of occupations that differ from and complement task-based proxies for skill. Wage regressions indicate that job-specific tools, which correspond to particular occupations, are associated with higher pay. Non-specific tools correlate to lower-paying sales, service and administrative occupations.
\end{abstract}

Keywords: Tool use, Occupation-specific skills, Job skills

JEL Classification: J31, J24

\section{Introduction}

Economists have long thought of human capital acquisition as a mix of general skills that are applicable across many jobs, and specific skills that have a disproportionate value to a particular job, occupation, or industry. The major limitation for this type of skill taxonomy is that specific skills are difficult to measure. Consequently, recent research has turned to identifying proxy measures of job-specific, occupation-specific, and industry-specific skills. The contribution of this paper is to propose that the tools used by workers in an occupation can serve as a new measure of occupation-specific skills.

Since it is difficult to identify concrete skill measures that are comparable across occupations (Cunningham and Mohr 2017), a relatively recent literature attempts to isolate particular characteristics of occupations that correspond to job skills. These papers often employ what Autor (2013) describes as the "task approach" to measuring skills. The goal is to measure the task requirements of an occupation and then link those tasks to the skills

\footnotetext{
*Correspondence: robert.mohr@unh.edu

2 Department of Economics, Paul College of Business and Economics,

University of New Hampshire, Durham, NH 03824, USA

Full list of author information is available at the end of the article
}

of the workers. ${ }^{1}$ Numerous authors have since uncovered new measures of tasks using a variety of data sources. A 2016 special issue in the Journal for Labour Market Research highlights measures of tasks in German (Rohrbach-Schmidt and Tiemann 2016), British (Green et al. 2016), Spanish (Mane and Miravet 2016) and US data (Handel 2016a).

We hypothesize that the tools used in an occupation are complementary to tasks. While a number of authors have focused on the link between information technology and the task content of occupations (e.g. Autor et al. 2003, 2006; Goos and Manning 2007; Spitz-Oener 2006), the literature has generally not studied other tools, beyond computers, used in work. An example illustrates how data on tools can provide new evidence to clarify distinctions made in this prior literature. One of the early and influential papers in this literature, Autor et al. (2003), studies how computerization alters job skill demands. The authors show support for the hypothesis that computers are substitutes for routine tasks, which require following explicit rules, and complements to cognitive tasks that involve problem solving or complex communication.

\footnotetext{
${ }^{1}$ Gathmann and Schönberg (2010) show that a task-based measure of skills explains a significant proportion of wage growth and Autor and Handel (2013) find that the inclusion of job tasks significantly improves the explanatory power of a wage regression. Autor (2013) and Autor and Handel (2013) provide review of this literature, including numerous studies not discussed here.
} 
We contend that information about a wide range of tools can provide deeper information about the particular products that might substitute for or complement specific types of tasks. Some commonly-used tools observed in our data include items like bar code readers, cash registers, and credit card readers, all of which we would expect to be associated with routine tasks. Other general tools like personal digital assistants or special purpose telephones might be complementary to cognitive tasks. Our descriptive statistics identify how the mean value of indices that characterize the tasks required of an occupation vary with the types of tools used in that occupation.

The contribution of this essay is to analyze tool use, especially those tools that are unique to a small number of occupations, to better categorize the skill requirements of various jobs. Tools relate closely to skills, since the mastery of any particular tool is a skill. The variation of tools across occupations allows a natural way to categorize these skills in terms of their specificity. Some tools (e.g. hammers, computers, or fax machines) are generalist and used in a wide range of occupations. Many other tools are very specific and used only in a very narrow range of occupations. The job-specific human capital these tools represent may indicate higher replacement costs of workers, and thus workers might earn higher wages; but alternatively, such job-specific human capital indicates fewer outside alternatives, which might lead to lower wages. Additionally, workers using outdated or obsolete tools may have developed particular complementary skills that compensate for the tools' weaknesses, which might be beneficial to this job but not transferable. Therefore it is an empirical question whether workers using job-specific tools will earn a wage premium for that skill. We show that the types of tools used in a particular occupation provide a measure for skills that correlates both to the task requirements of a job and to wages. Very few prior papers use data from a wide range of tools or technologies. Handel (2016a) highlights the need for better measures of tools and technologies, and presents survey data from US workers to measure the use of heavy machinery and machine tools as well as related skills like machine set-up and repair or the programming and operation of robots. Snower and Goerlich (2013) use data about the use of approximately 30 tools to study the relationship between multitasking and wages.

The regression analyses in this paper study the role of tool use in determining occupational wage premiums. Our approach relies on measuring the number of tools typically used in an occupation as well as measuring the number of job-specific tools that are used only in a narrow range of occupations. We report how tool use correlates to more commonly used measures of job tasks. We then test whether tool use helps explain wages at the occupation level. In particular, we ask if the either the aggregate number of tools or the number of job-specific tools correlates to wages, and if that relationship varies by the type of occupation.

The remainder of this paper is organized as follows. Section 2 discusses several theoretical and conceptual issues relevant to our empirical analyses. Section 3 discusses the O*NET data and develops a measure of tool specificity. Section 4 studies the relationship between tool specificity and wages. Section 5 concludes.

\section{Conceptual discussion}

A Mincer wage regression is the most common way to measure returns to skill. Such a regression typically takes the form:

$$
\ln \left(w_{i}\right)=\alpha+\beta_{1} S_{i}+\beta_{2} T_{i}+\beta_{3} T_{i}^{2}+\gamma X_{i}+v_{i}
$$

where $w_{i}$ represents the wage for worker $i, S_{i}$ measures educational attainment, $T_{i}$ measures either age or experience, and $X_{i}$ is a vector of individual-level covariates like gender or race. In its simplest form, this regression uses schooling and experience to proxy for skills. Since these measures are not specific to occupations, a major challenge is to measure the particular skills needed in individual jobs.

Economists have proposed a number of measures that may proxy for the skill requirements of work, including information about specific job tasks (Autor and Handel 2013), requirements of occupations (Levenson and Zoghi 2010), or in the case of this paper, tools. Unfortunately, including any of these proxies directly into a wage regression can lead to another source of bias. A reduced-form expression like Eq. 1 does not control for selection into occupations. Estimating the equation with either tasks or tools included individually would quite likely produce negative coefficients for those tasks or tools that are used frequently at low-wage jobs and less frequently at highwage jobs. Such a cross-sectional result would of course not mean that acquiring the skills to perform a given task or use a given tool negatively affects wages.

In cross-sectional data where the proxy for skill is measured only at the occupational level the potential for biased estimators in a Mincer wage regression can't be eliminated. One option is to develop alternative models for the relationship between wages and skills, as in Autor and Handel (2013) or Firpo et al. (2011), but such models still require variation at the individual level and may have relatively weak testable implications. Barring the 
use of such an alternative model, one must acknowledge the limitations of including the skill proxies in the wage regression, summarize the bundle of task or tool measures into a small number of indices that are hopefully less susceptible to bias, and proceed with the knowledge that such an imperfect measure is likely better than failing to include proxies for specific skills at all.

In order to assess the validity of tool use as a measure of skills, we start by counting the total number of tools used in an occupation and we define measures to identify job-specific and general tools. We explore the relationship between tool specificity and characteristics of occupations and show that the measures of tool use correlate to established, task-based, proxies for skill. We study how the inclusion of tools in a wage regression helps explain occupational wage differentials.

\section{Data and descriptive statistics}

Occupation-specific information comes from the 2010 Occupational Information Network (O*Net, or ONET) database, which is compiled by the US Department of Labor and contains a broad range of descriptors for various occupations. Although many prior studies use these data, work in economics has to our knowledge failed to exploit the Tools and Technologies Supplement (T2), which contains a thorough inventory of the tools used in particular occupations. An important limitation is that O*Net does not measure variation within occupations, so it does not indicate how intensively a particular tool is used, the age of the tools, or what proportion of workers within an occupation use a given tool. Hence, the data allow us to study the occupational-level relationship to wages but do not allow us to identify heterogeneity in tool use or job tasks within an occupation (see Handel 2016b for additional discussion of $\mathrm{O}^{*} \mathrm{Net}$ and T2).

The Department of Labor's O*Net database collects data on 774 "high demand" occupations. Dierdorff et al. (2006) describe the Tools and Technologies Supplement, including the details of data collection and classification. Tools are identified by occupation, with the criteria for inclusion being that tools are:

those items necessary to carry out central functions required by an occupational incumbent's work role and responsibilities. In addition to being essential to occupational performance, T2 items must have an expectation of a training requirement that ranges from a minimum of at least some on-the-job training, initial supervision, or 'demonstration of use', to more formal training or vocational education. (Dierdorffet al. 2006)
By definition, tools must be proxies for occupation-specific skills, since they "have an expectation of a training requirement," a requirement that is occupation-specific. The 2010 O*Net data contain 3271 tools that workers need to perform their occupations.

Because workplace tools are also products purchased by businesses, they are listed in the United Nations Standard Products and Services Code (UNSPSC) and classified within the T2 using a taxonomy that categorizes each tool by "commodity," "class," "family" and "segment." The basic design rule of this taxonomy is to group tools with a "common function, purpose or task" (Granada Research 2001). For example, the tool "livestock scales" belongs to the class "weight measuring instruments," the family "measuring and observing and testing instruments" and segment, "laboratory and measuring and observing and testing equipment." Importantly for our purposes, the UNSPSC taxonomy is based on the product features of the tool, rather than an attempt to classify tools according to occupation or skill. In a retail setting, tools in the same family or class would likely be located in a common aisle. Thus, the taxonomy provides a measure, separate and independent from other skill measures, which we can link to job tasks; particular segments of tools may be more complementary to particular types of tasks. Furthermore, tools within the same segment may require similar skills, so that the number of tool segments (rather than the number of tools) can control for the diversity of skills in an occupation.

The average number of tools and tool families used per job, by major occupation (weighted by 2010 American Community Survey employment totals), is summarized in Table $1 .^{2}$ The average worker uses nearly 58 different tools; while many of these may be quite similar to one another, as in bolt cutters, cable cutters and wire cutters, the average worker also uses approximately 13 different families of tools (e.g. hand tools or heavy construction machinery and equipment). At both levels of aggregation there are large differences by major occupation. Far fewer tools are used in sales, service and administrative occupations relative to the blue-collar occupations. Although not shown in the table, there is also significant variation within the broad occupational categories. For example, workers in service occupations use far more tools than workers in administrative positions. Economists use just six tools: desktop calculators, desktop computers, mainframe computers, notebook computers, personal computers and scanners. ${ }^{3}$

\footnotetext{
2 The values in Table 1 are similar to Dierdorff et al's Table 3, which reports unweighted means for tool use.

${ }^{3}$ Managerial occupations are excluded from our regressions since tool use is unlikely to be a good proxy for human capital for these occupations.
} 
Table 1 Number of different tools and tool families used, by major occupation. Source: O*NET 15.0: T2 supplement

\begin{tabular}{|c|c|c|c|c|c|}
\hline & Category definition & Full sample & Professionals & $\begin{array}{l}\text { Sales, service } \\
\text { and administrative }\end{array}$ & Blue collar \\
\hline Number of tools & & 57.7 & 93.6 & 28.3 & 78.4 \\
\hline Number of tool families & & 13.0 & 18.4 & 8.7 & 16.0 \\
\hline Job-specific tools & $\begin{array}{l}\text { Number of tools used by } \\
0-2 \% \text { of other workers }\end{array}$ & 22.8 & 48.6 & 9.0 & 23.0 \\
\hline General tools & $\begin{array}{l}\text { Number of tools used by } \\
15+\% \text { of other workers }\end{array}$ & 9.9 & 11.3 & 8.1 & 11.9 \\
\hline
\end{tabular}

Figures show the average number of tools used per worker, weighted by 2010 ACS employment totals

Given the training requirements associated with the tools in the T2 supplement, the mastery of the tools of an occupation represents a form of human capital. In occupations that use many tools or job-specific tools, this human capital is likely to be occupation-specific. If a given occupation tends to use tools that are more general, meaning that many workers in other occupations use the very same tools, then this human capital is not occupation-specific. To define tool specificity we weight each occupation with respect to its employment level (using the 2010 American Community Survey) and then calculate the percentage of workers outside of a given occupation that use a particular tool.

Choosing the precise threshold (i.e. the percentage of workers using a tool) to label a tool as either jobspecific or general is somewhat arbitrary, but our goal is to define these terms in a way that is both true to their meanings (i.e. job-specific tools are closely associated to particular occupations) and also assures sufficient variation across occupations. Figure 1 shows the distribution of other tool users across tools. Nearly $40 \%$ of the tools in $\mathrm{T} 2$ are used by $0-2 \%$ of other workers. Based on this natural break in the data, it seems reasonable to define a job-specific tool as one that is used by less than $2 \%$ of other workers. Since our goal, though, is to measure wages for workers based on their use of job-specific tools, we want to ensure that the threshold we select gives us enough variation across workers. We therefore consider how a slightly higher or lower threshold would affect the number of workers identified as using job-specific tools. As indicated in appendix Table 8 , half of all workers use between 0 and 3 job-specific tools when we apply the most restrictive definition (used by less than $.5 \%$ of workers outside of that occupation) of "job-specific". That value increases rapidly as we vary the threshold for specificity by $1 / 2$ percentage point increments. Ultimately, we choose to define a job-specific tool as one that is used by between
$0 \%$ and $2 \%$ of workers outside of that occupation. As shown in row 4 of Table 8 , this definition ensures substantial variation in the number of such tools across workers; $90 \%$ of all workers $(945,708$ of $1,048,107)$ and $84 \%$ of all occupations ( 252 of 300 ) in our sample use at least one specific tool. We define a general tool as one that is used by at least $15 \%$ of all workers outside of that occupation.

The bottom section of Table 1 shows the number of job-specific and general tools by major occupation. Of the 58 tools used by a typical worker, 23 are specific and 10 are general. There is significant variation in the number of job-specific tools used across occupation groups. Blue collar workers use the most tools, the majority of which are job-specific.

Only 37 tools meet the definition of "general," meaning that more than $15 \%$ of workers observed in the American Community Survey use them. Table 1 suggests less variation in general tools. Since expertise in general tools may proxy for general human capital that is valuable across numerous occupations, we list these tools individually in Table 2. The most commonly used tools are computers,

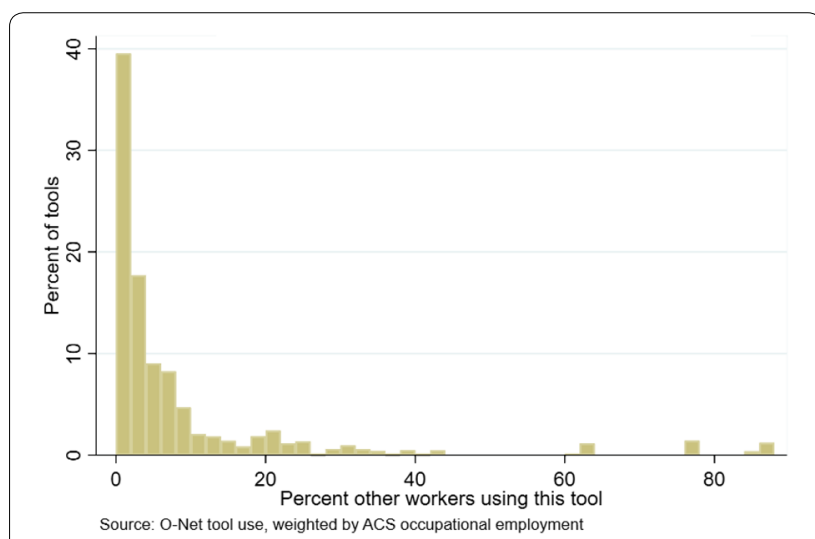

Fig. 1 Specificity of tool use 
Table 2 Percent of workers using most commonly-used tools (general tools). Source: O*NET 15.0:T2 supplement

\begin{tabular}{|c|c|c|c|}
\hline Tool & $\%$ using & Tool & \% using \\
\hline Personal computers & 86.05 & Bar code reader equipment & 21.58 \\
\hline Desktop computers & 77.49 & Power saws & 21.54 \\
\hline Notebook computers & 62.37 & Air compressors & 21.40 \\
\hline Laser printers & 43.00 & Power drills & 21.24 \\
\hline Scanners & 38.84 & Portable data input terminals & 20.68 \\
\hline Personal digital assistant PDAs or organ & 35.58 & Desktop calculator & 20.28 \\
\hline Photocopiers & 33.55 & Tape measures & 20.09 \\
\hline Laser fax machine & 33.35 & Cash registers & 19.81 \\
\hline Screwdrivers & 31.78 & Calipers & 19.59 \\
\hline Special purpose telephones & 31.03 & Digital camcorders or video cameras & 19.33 \\
\hline Hammers & 29.65 & Safety glasses & 19.18 \\
\hline Digital cameras & 25.93 & Electronic funds transfer point of sale & 18.41 \\
\hline Two way radios & 24.61 & Protective gloves & 18.15 \\
\hline Ladders & 24.45 & Levels & 16.91 \\
\hline Forklifts & 24.13 & Power grinders & 16.82 \\
\hline Adjustable wrenches & 23.97 & Liquid crystal display projector & 15.84 \\
\hline Tablet computers & 23.12 & Global pos. system GPS receiver & 15.45 \\
\hline Pocket calculator & 22.10 & Goggles & 15.24 \\
\hline Adjustable widemouth pliers & 21.78 & & \\
\hline
\end{tabular}

Percentage of workers using a given tool, weighted by 2010 ACS employment totals

printers, scanners, photocopiers, and fax machines. Consistent with data from other surveys (e.g. Zoghi and Pabilonia 2007), O*Net data indicate that nearly $90 \%$ of workers use a computer on the job. Beyond information technology, which has been incorporated into numerous prior studies (e.g. Autor et al. 1998; Arabsheibani and Marin 2006; Morissette 1998; Pabilonia and Zoghi 2005), the list in Table 2 indicates a diverse set of tools associated with general human capital.

In addition to providing information about tool use, O*Net data also provide direct information about the cognitive and manual requirements and physical risks associated with occupations. Acemoglu and Autor (2011) and Autor and Handel (2013) identify particular O*Net measures to create additive indices of the task requirements of jobs. Based on the description in Acemoglu and Autor (2011), we replicate four indices, which they name Non-routine cognitive, Routine cognitive; Routine manual; and Non-routine manual. Cognitive occupations emphasize analytical, creative and interpersonal skills. Occupations that score highly on the routine measure emphasize repetition, pace, accuracy and the control of machines or processes. Each index is created by summing the responses of between three and seven specific scaled measures of tasks. ${ }^{4}$ In addition to the task indices, we use the same methodology to create an index to measure the physical risks of work. We control for risk since wages may reflect a compensating differential, and the use of tools are likely to correlate to the risk of injury.

Table 3 presents correlation coefficients between the tools used in an occupation, the task-based indices, and risk. The high correlation between the total number of tools and the number of job-specific tools is to some extent an artifact of how the measures are created. There are few general tools, some of which (like computers) are used by nearly all workers, so much of the variation in tool use is driven by the variation in job-specific tools. The correlations between the task indices and the three measures of tool use range from -.09 to .27 . All three measures of tool use are positively correlated to non-routine cognitive tasks. We interpret this correlation to indicate that a worker who uses many different tools is less likely to have a job that is repetitive or easily automated. If the worker must decide which tools or combinations of tools are appropriate for a particular situation, then such decision-making is a cognitive task.

\footnotetext{
${ }^{4}$ Acemoglu and Autor (2011) apply labor supply weights and standardize each scale to have a mean zero and standard deviation one. David Autor has helpfully published the code for all of these steps on his web page, so an exact replication is possible.
} 
Table 3 Correlation coefficients. Sources: O*NET 15.0 Database (incl. T2 supplement); American Community Survey 2010

\begin{tabular}{|c|c|c|c|c|c|c|c|c|}
\hline & $\begin{array}{l}\text { Non-routine } \\
\text { cognitive }\end{array}$ & $\begin{array}{l}\text { Non-routine } \\
\text { manual }\end{array}$ & $\begin{array}{l}\text { Routine } \\
\text { cognitive }\end{array}$ & Routine manual & Risk & \#Tools & $\begin{array}{l}\text { \#Job- } \\
\text { specific } \\
\text { tools }\end{array}$ & \#General tools \\
\hline Non-routine cognitive & 1 & & & & & & & \\
\hline Non-routine manual & -.28 & 1 & & & & & & \\
\hline Routine cognitive & .32 & -.33 & 1 & & & & & \\
\hline Routine manual & -.55 & .68 & -.20 & 1 & & & & \\
\hline Risk & -.26 & .76 & -.30 & .71 & 1 & & & \\
\hline Number of tools & .25 & .08 & -.09 & .06 & .27 & 1 & & \\
\hline \#Job-specific tools & .26 & -.03 & -.01 & -.03 & .14 & .95 & 1 & \\
\hline \# General tools & .27 & .09 & -.02 & -.02 & .23 & .61 & .42 & 1 \\
\hline
\end{tabular}

Table indicates correlation coefficients from the full sample of workers using occupation weights. N=1,041,239

Although the correlations between the number of tools used and the other three task indices are low, task indices do vary with the types of tools used. Table 4 explores the relationship between tool segments (the broadest categorization of tools in the UNSPSC taxonomy) and task indices. An individual cell indicates the mean value of a task index for workers in occupations that use at least one tool from a given segment. Because task indices are normalized to have a population mean of zero and a standard deviation of one, the magnitudes in the table are easy to interpret; values greater than .5 in absolute value are italicized. Many segments have a strong positive association to the non-routine manual or routine manual task indices. Tools may proxy better for skills where tasks tend to have "blind spots", i.e. in blue-collar occupations; and vice versa, task indices may proxy better where cognitive requirements are important, and tools tend to be less discriminative, i.e. within professional or managerial jobs. Although not depicted in the table, the relationship between the types of tools used and the task indices also holds at the level of individual tools. For example, workers using at least one of three of the tools discussed in the introduction, bar code readers, cash registers, and credit card readers, have higher mean values for the two indices identifying routine tasks. Individuals using personal digital assistants or special purpose telephones have higher values for the indices identifying cognitive tasks.

\section{Results and discussion}

In order to link tool use to wages, we draw individuallevel data on hourly wages, demographic information, and occupation from the 2010 American Community Survey. ${ }^{5}$ We estimate a wage regression, as described in

\footnotetext{
5 The American Community Survey estimates hourly wages as annual income divided by the product of weeks worked and the usual hours per week.
}

Eq. (1), and include the following occupation-specific measures: indices for cognitive, non-routine, or risky occupations, the total number of tools along with its square term, the number of job-specific tools, and the number of job-specific tools squared. We control for the standard worker demographic variables: age, education, race, gender, disability and marital status. We exclude managers, who use very few tools overall and have no tools that are specific to their occupation. Since the task indices and the use of tools vary only by occupation, standard errors are clustered; coefficients therefore indicate occupation-level differences.

Table 5 shows the results of five different OLS estimations for a wage regression, where the log of weekly wages is the dependent variable. The first column uses the full population of workers, excluding managers. This regression estimates Eq. (1) including task and risk indices, the total number of tools, and the number of tools squared. Because we hypothesize that job-specific tools will best proxy the portion of human capital connected to an occupation, we add the number of job-specific tools (still controlling for all other tools used) as an explanatory variable in column 2 . Next, we partition the data by major occupation group into professional; sales, service and administrative; and blue collar occupations and report these results in columns 3-5.

Column 1 of Table 5 indicates no statistically significant relationship between the number of tools used in an occupation and the occupational level wage premium in a model that pools occupations. Column 2 shows that occupational wages do correlate positively to the number of job-specific tools. Workers who must learn and master numerous tools specific to their jobs earn a wage premium. Control variables for worker's demographic characteristics and the measures for the tasks and risks associated with an occupation have signs and significance levels that are largely consistent with prior work. 
Table 4 Mean values of task indices, by tool segment. Sources: O*NET 15.0 Database (incl. T2 supplement); American Community Survey 2010

\begin{tabular}{|c|c|c|c|c|c|}
\hline \multirow[t]{2}{*}{ Segment title } & \multirow{2}{*}{$\begin{array}{l}\text { Percentage of workers } \\
\text { using segment }\end{array}$} & \multicolumn{4}{|c|}{ Mean values for task indices } \\
\hline & & $\begin{array}{l}\text { Non-routine } \\
\text { cognitive }\end{array}$ & $\begin{array}{l}\text { Routine } \\
\text { cognitive }\end{array}$ & $\begin{array}{l}\text { Non-routine } \\
\text { manual }\end{array}$ & Routine manua \\
\hline IT, Broadcasting and Telecommunications & 98.2 & -.12 & -.04 & .04 & .04 \\
\hline Office Equipment, Accessories \& Supplies & 72.0 & -.05 & .06 & -.09 & -.06 \\
\hline Defense, Law Enfor., Security, \& Safety Equip. & 47.0 & -.18 & -.26 & .40 & .40 \\
\hline Lab., Measuring \& Obs. \& Testing Equip. & 45.9 & .19 & -.12 & .37 & .21 \\
\hline Tools and General Machinery & 45.2 & -.14 & -.34 & .47 & .39 \\
\hline Domestic Appl., Supplies \& Cons. Electr. Prod. & 40.6 & .17 & -.14 & -.03 & -.26 \\
\hline Material Handling, Conditioning, Storage Mach. & 40.0 & -.63 & -.48 & .73 & .88 \\
\hline Printing, Photo, \& A.V. Equip. \& Supplies & 38.2 & .44 & .08 & -.32 & -.51 \\
\hline Distrib. \& Conditioning Syst., Equip \& Comp. & 34.0 & -.27 & -.35 & .59 & .55 \\
\hline Industr. Manuf. \& Processing Machin. \& Acc. & 30.4 & -.23 & -.36 & .55 & .68 \\
\hline Structures, Bldg, Constr., Mfg Comp. \& Suppl. & 27.5 & -.36 & -.50 & .51 & .57 \\
\hline Service Industry Mach., Equip. \& Supplies & 26.1 & -.51 & -.03 & -.21 & .10 \\
\hline Cleaning Equipment and Supplies & 24.1 & -.26 & -.69 & .43 & .48 \\
\hline Commercial, Mil. \& Priv. Vehicles & 24.0 & -.11 & -.45 & 1.00 & .43 \\
\hline Medical Equip., Accessories \& Supplies & 23.6 & .08 & .00 & -.10 & -.27 \\
\hline Manufacturing Components \& Supplies & 20.4 & -.12 & -.49 & .64 & .68 \\
\hline Building \& Constr. Machinery \& Accessories & 18.1 & -.76 & -.78 & 1.24 & 1.17 \\
\hline Power Generation and Distr. Machinery & 13.8 & .05 & -.20 & .87 & .79 \\
\hline Music Inst, Games, Toys, Arts \& Crafts Eq. & 12.6 & .72 & -.48 & -.47 & -.89 \\
\hline Electr. Syst., Lighting, compnts, access., suppl. & 12.3 & .72 & -.04 & .01 & -.21 \\
\hline Farming, Fish., Forest. \& Wildlife Mach. \& Acc. & 11.5 & .35 & -.50 & .28 & .20 \\
\hline Mining, Well Drilling Machinery \&Accessories & 9.1 & -.04 & -.47 & .69 & .73 \\
\hline Furniture and Furnishings & 7.7 & .08 & -.63 & -.03 & -.31 \\
\hline Sports and Rec. Equipment and Supplies & 6.8 & .81 & -.19 & -.10 & -.46 \\
\hline Electronic Components and Supplies & 6.3 & .11 & -.02 & .37 & .53 \\
\hline Published Products & 6.1 & .27 & -.31 & .25 & .01 \\
\hline Chemicals incl. Bio Chem. and Gas Materials & 5.4 & .45 & -.20 & .73 & .38 \\
\hline Apparel, Luggage \& Personal Care Products & 5.0 & .66 & -.19 & -.09 & -.39 \\
\hline Live Plant \& Animal Material and Accessories & 4.2 & .72 & -.52 & -.17 & -.44 \\
\hline Timepieces and Jewelry and Gemstone Prod. & 1.3 & .09 & -.67 & .49 & .65 \\
\hline Paper Materials and Products & 1.1 & -.55 & 1.25 & -.83 & -.55 \\
\hline
\end{tabular}

Table indicates mean values of the task indices for workers using at least one tools from given segment, with occupation weights. Values exceeding .5 in abs. value in italics. Segments used by fewer than 4 occupations excluded

Amongst professional and blue-collar workers, where job-specific tool use is highest, we hypothesize that the mastery of tools is an important aspect of occupationspecific human capital. The results in columns 3 and 5 support this hypothesis; the coefficient on the number of job-specific tools is statistically significant and positive in both cases. Evaluating the marginal effects for the full sample, professional and blue collar workers at the respective sample means of $22.8,48.6$, and 23.0 jobspecific tools (see Table 1), suggests a modest but economically meaningful relationship. An increase of 10 job-specific tools, holding all else constant, would correspond to an increase in predicted earnings of $3.8 \%, 6.2 \%$, and $2.5 \%$ for the full sample, professional, and blue-collar workers, respectively. For sales, service and administrative workers, who typically use fewer tools overall, most of which are general, job-specific tools are not correlated to wages. The total number of tools used, conditional on job-specific tools, correlates negatively to wages. This suggests that the non-specific tools used in this sector are not complementary to skills. 
Table 5 Wage regressions

\begin{tabular}{|c|c|c|c|c|c|}
\hline & Full sample & Full sample & Professional & Sales, serv., and admin & Blue collar \\
\hline Non-white & $-.0353^{* * *}(.0069)$ & $-.0378^{* * *}(.0064)$ & $-.0017(.0121)$ & $-.0336^{* * *}(.0068)$ & $-.0692^{* * *}(.0102)$ \\
\hline Female & $-.2211^{* * *}(.0169)$ & $-.2197^{* * *}(.0169)$ & $-.2214^{* * *}(.0203)$ & $-.1771 * * *(.0179)$ & $-.1933^{* * *}(.0164)$ \\
\hline Married & $.0945^{* * *}(.0075)$ & $.0943^{* * *}(.0074)$ & $.0773 * * *(.0125)$ & $.0842^{* * *}(.0094)$ & $.1229^{* * *}(.0064)$ \\
\hline Age & $.0511^{* * *}(.0024)$ & $.0516^{* * *}(.0024)$ & $.0614^{* * *}(.0040)$ & $.0488^{* * *}(.0031)$ & $.0519^{* * *}(.0026)$ \\
\hline Age squared & $-.0005^{* * *}(.0000)$ & $-.0005^{* * *}(.0000)$ & $-.0006^{* * *}(.0000)$ & $-.0005^{* * *}(.0000)$ & $-.0005^{* * *}(.0000)$ \\
\hline High school & $.1161^{* * *}(.0109)$ & $.1166^{* * *}(.0105)$ & $.0277(.0323)$ & $.0923^{* * *}(.0116)$ & $.1588^{* * *}(.0095)$ \\
\hline Some college & $.1896^{* * *}(.0147)$ & $.1886^{* * *}(.0135)$ & $.1084 * * *(.0365)$ & $.1686^{* * *}(.0132)$ & $.2403^{* * *}(.0199)$ \\
\hline College degree & $.4644^{* * *}(.0226)$ & $.4642^{* * *}(.0225)$ & $.4750^{* * *}(.0349)$ & $.3778^{* * *}(.0231)$ & $.3442^{* * *}(.0427)$ \\
\hline Non-routine cogn. & $.0667^{* * *}(.0233)$ & $.0710^{* * *}(.0222)$ & $.1147^{*}(.0624)$ & $.1174 * * *(.0237)$ & $.1280^{* * *}(.0185)$ \\
\hline Non-routine manual & $-.0180(.0286)$ & $-.0190(.0292)$ & $-.1225^{* *}(.0575)$ & $-.0894^{* *}(.0438)$ & $-.0074(.0171)$ \\
\hline Routine cognitive & $.1029^{* * *}(.0222)$ & $.0906^{* * *}(.0216)$ & $.1707^{* * *}(.0452)$ & $.0646^{* * *}(.0197)$ & $.0460^{* * *}(.0222)$ \\
\hline Routine manual. & $-.0928^{* *}(.0367)$ & $-.0900^{* * *}(.0338)$ & $.0191(.0797)$ & $-.1285^{* * *}(.0433)$ & $-.0090(.0190)$ \\
\hline Risk & $.1029^{* * *}(.0290)$ & $.0949 * * *(.0286)$ & $.0370(.0445)$ & $.1834^{* * *}(.0365)$ & $.0657^{* * *}(.0179)$ \\
\hline \# Job-specific tools & & $.0387^{* *}(.0170)$ & $.0734^{* *}(.0288)$ & $.0406(.0670)$ & $.0720^{* *}(.0331)$ \\
\hline Specific squared & & $-.0002(.0009)$ & $-.0011(.0011)$ & $-.0038(.0093)$ & $-.0101^{* * *}(.0029)$ \\
\hline Total tools & $-.0020(.0074)$ & $-.0181 *(.0106)$ & $-.0268(.0178)$ & $-.1082^{* * *}(.0363)$ & $-.0006(.0139)$ \\
\hline Total tools squared & $.0000(.0001)$ & $-.0001(.0004)$ & $.0000(.0005)$ & $.0075^{* * *}(.0026)$ & $-.0002(.0006)$ \\
\hline Occupation indicators & Yes & Yes & No & No & No \\
\hline Observations & $1,041,239$ & $1,041,239$ & 295,419 & 497,121 & 248,699 \\
\hline R-squared & .326 & .328 & .285 & .245 & .210 \\
\hline
\end{tabular}

Dependent variable is natural log of earnings. Robust standard errors in parentheses. Constant not reported. Occupation indicators control for 10 major occupation groups. Tools measured in 10 tool increments

${ }^{* * *} \mathrm{p}<.01,{ }^{* *} \mathrm{p}<.05,{ }^{*} \mathrm{p}<.1$

In order to further explore the relationship between the number of job-specific tools used in an occupation and wages, we estimate regressions for nine subsamples and report results in Table 6 . We start by partitioning the full sample by gender, since participation in tool-intensive occupations often differs by gender. Many tool-intensive

Table 6 Wage regressions by major occupation

\begin{tabular}{llllll}
\hline & Male & Female & Service & Sales & Admin \\
\hline \# Job-specific tools & $.0341^{*}(.0184)$ & $.0403^{* *}(.0193)$ & $.0350(.0558)$ & $2.9851^{* * *}(.4202)$ & $.1529(.2660)$ \\
Specific squared & $-.0001(.0008)$ & $-.0001(.0010)$ & $-.0023(.0088)$ & $-4.2719^{* * *}(.7879)$ & $-.1347(.2012)$ \\
Total tools & $-.0134(.0114)$ & $-.0220^{*}(.0119)$ & $-.0653^{*}(.0340)$ & $-.2292(.1671)$ & $-.2177^{*}(.1077)$ \\
Total tools squared & $-.0002(.0004)$ & $-.0000(.0004)$ & $.0034(.0028)$ & $-.1412^{* *}(.0460)$ & $.0498^{*}(.0268)$ \\
Number of clusters & 300 & 300 & 39 & 13 & 24 \\
Observations & 525,898 & 515,341 & 207,764 & 132,593 & 156,764 \\
R-squared & .344 & .296 & .187 & .317 & .178 \\
\hline & Construction & Installation and repair & Production & Transportation \\
\hline \# Job-specific tools & $.0884(.0808)$ & $-.0666(.1188)$ & $-.0849^{*}(.0443)$ & $.3589^{* * *}(.0743)$ \\
Specific squared & $-.0250^{* *}(.0104)$ & $.0051(.0214)$ & $.0089(.0057)$ & $-.0739^{* * *}(.0187)$ \\
Total tools & $.0044(.0295)$ & $.0955^{*}(.0532)$ & $.0635^{* *}(.0255)$ & $.0274(.1053)$ \\
Total tools squared & $.0010(.0010)$ & $-.0046(.0029)$ & $-.0022^{*}(.0011)$ & $-.0059(.0128)$ \\
Number of clusters & 31 & 23 & 31 & 21 \\
Observations & 58,020 & 39,144 & 56,848 & 81,993 \\
R-squared & .161 & .194 & .237 & .187 \\
\hline
\end{tabular}

Dependent variable is natural log of earnings. Robust standard errors in parentheses. Each regression includes full set of control variables, as in Table 5. Male and Female samples include occupation indicators to control for 10 major occupation groups. Tools measured in 10 tool increments

${ }^{* * *} p<.01,{ }^{* *} p<.05,{ }^{*} p<.1$ 
blue-collar occupations are predominantly male. Several tool-intensive professional and service occupations, in particular in health care and nursing, are predominantly female. The remaining seven regressions reported in Table 6 estimate the relationship between tool use and wages for each of the major occupations within the sales, service, and administrative, and blue-collar designations. While these regressions are useful in identifying whether statistically significant results are driven by particular major occupations, such disaggregation comes at a cost. Our source of variation is across 3-digit occupations, and each major occupation contains only a small number of 3-digit occupation codes. For this reason, we exclude Farming, Fishing and Forestry, which has only six occupations. The number of 3-digit occupation clusters for each remaining subsample is shown in Table 6.

Table 6 is split into two sections (top and bottom of the table) and reports results from 9 different regressions. Each regression uses a full set of control variables, including the task, risk, and demographic measures from Table 5, but we report only the coefficients on the number of job-specific tools, the total number of tools, and their squared terms. The first two columns at the top of the table report results for the male and female subsamples, the remaining three columns at the top of the table report results separately for sales, service and administrative occupations, and the four columns at the bottom of the table report results for four of the major blue-collar occupations.

The results in Table 6 are mostly consistent with the hypothesis that any wage premium associated with tool use is most likely to be linked to job-specific tools. Amongst the 7 regressions partitioning the sample by major occupation, the coefficient for job-specific tools has a positive sign 5 times. Not surprisingly, given the small number of occupations in each regression, coefficients are generally not statistically significant. Marginal effects (not reported) match the coefficients in sign and statistical significance. The coefficient on the total number of tools, which given the control for job-specific tools captures variation in tools that are used across multiple occupations, is negative in all five regressions in the top section of the table. This is consistent with Table 5 and suggests that, although the human capital afforded by such tool mastery is widely transferable, it is not specific enough to generate a wage premium outside of a few blue-collar occupations.

Given that Tables 5 and 6 report statistical significance of job-specific tools, we check whether our results are sensitive to how we define the term job-specific. Instead of defining a job-specific tool as one that is used by less than $2 \%$ of workers outside of an occupation, we allow the definition to vary in $.5 \%$ point increments, as

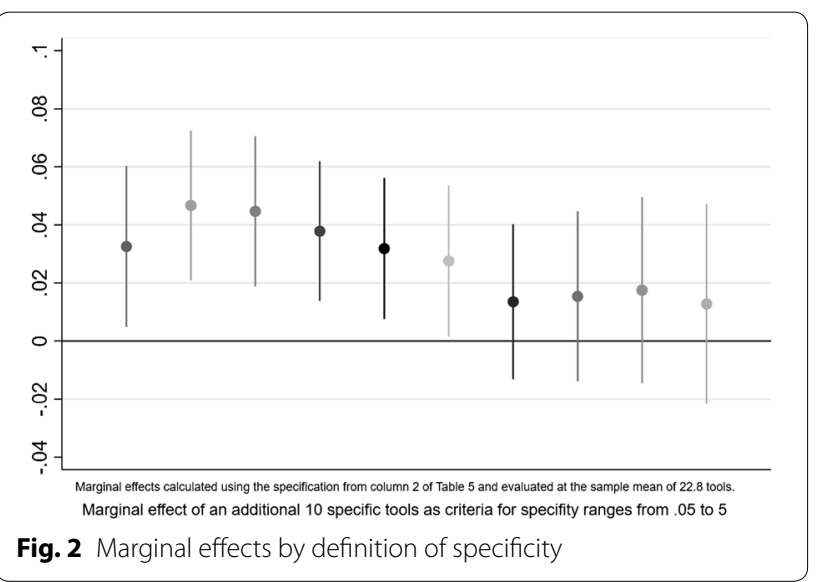

in Table 8, ranging from .5 to $5 \%$ of workers outside of an occupation. These alternate definitions of specificity produce results consistent with our conclusion that job-specific tools are associated with wage premiums. Figure 2 shows the marginal effects of job-specific tools, evaluated at 22.8 tools, using a wage regression with the full population of workers (i.e. the specification used in column 2 of Table 5). The far left spike represents the $90 \%$ confidence interval using the definition of specificity which requires that no more than $.5 \%$ of workers outside of an occupation use the tool, the second spike uses the definition that no more than $1 \%$ of workers outside of the occupation use the tool, etc. The positive relationship between wages and job-specific tools is robust for values near or below our chosen threshold of $2 \%$, but that magnitude and statistical significance declines as the definition becomes less restrictive.

A final set of regressions revisits the implications of Tables 5 and 6 using specifications that do not require defining job-specific tools. We reconsider columns 2-5 of Table 5. Instead of including job-specific tools, we include only the total number of tools and control for either the generality or diversity of tools. The number of general tools measures generality; the number of tool segments measures diversity. Using tools from multiple different segments may be an indication that a worker's skills are diverse and therefore more general. Given the prior results, we expect that coefficients on the number of general tools or the number of tool segments will be insignificant or negative, indicating no occupational wage premiums for these general skills. Given the control for generality or diversity, the remaining variation in the number of tools used in an occupation will now indicate variation in occupation-specific skills. Therefore, we expect the number of tools to be more positively correlated to wages.

Table 7 reports results. The four columns at the top of the table control for the number of general tools. The 
Table 7 Wage regressions without job-specific tools

\begin{tabular}{lllll}
\hline & Full sample & Professional & Sales, serv., and admin & Blue collar \\
\hline \# General tools & $-.0442(.1015)$ & $-.2556^{*}(.1525)$ & $-.2221(.2016)$ & $-.0528(.0905)$ \\
General squared & $-.0161(.0407)$ & $.0495(.0528)$ & $.1504(.1287)$ & $.0065(.0334)$ \\
Total tools & $.0044(.0081)$ & $.0215^{* *}(.0098)$ & $-.0914^{* * *}(.0281)$ & $.0309^{* *}(.0121)$ \\
Total tools squared & $-.0000(.0001)$ & $-.0003^{* *}(.0002)$ & $.0074^{* *}(.0027)$ & $-.0016^{* * *}(.0006)$ \\
Occupation indicators & Yes & No & No & No \\
Observations & $1,041,239$ & 295,419 & 497,121 & 248,699 \\
R-squared & .327 & .281 & .246 & .207 \\
& & $-.0186^{*}(.0099)$ & $-.0073(.0080)$ & $-.0109^{* *}(.0054)$ \\
\#Tool segments & $-.0166^{* * *}(.0062)$ & $.0244^{* *}(.0111)$ & $-.0881^{* * *}(.0257)$ & $.0384^{* * *}(.0135)$ \\
Total tools & $.0093(.0080)$ & $-.0003^{* *}(.0002)$ & $.0071^{* * *}(.0022)$ & $-.0018^{* * *}(.0007)$ \\
Total tools squared & $-.0001(.0001)$ & No & No & No \\
Occupation indicators & Yes & 295,419 & 497,121 & 248,699 \\
Observations & $1,041,239$ & .280 & .245 & .208 \\
R-squared & .328 & & \\
\hline
\end{tabular}

Each column reports results of two regressions. Dependent variable is natural log of earnings. Robust standard errors in parentheses. Each regression includes full set of control variables, as in Table 5. Occupation indicators control for 10 major occupation groups. Tools measured in 10 tool increments

*** $\mathrm{p}<.01,{ }^{* *} \mathrm{p}<.05,{ }^{*} \mathrm{p}<.1$

four columns at the bottom of the table control for the number of tool segments. Coefficients on the measures of generality and diversity are insignificant or negative. The number of tools is now positively associated with wages for professional and blue-collar workers. The coefficient on the number of tools for sales, service and administrative occupations, which use few tools, are contrary to our expectation but similar to those in Table 5 .

We perform several additional robustness checks using alternate measures for job-specific tools applied to the specifications presented in Table 5. First, we include as a regressor the proportion, not number, of job-specific tools within an occupation. Second, we redefine the term job-specific by professional; sales, service and administrative; and blue collar occupations. In other words, a tool is defined as specific for a blue-collar occupation only if it used by few other blue-collar workers, rather than few workers overall. These alternate specifications produce results consistent with our main findings. The percentage and number of job-specific tools typically have positive associations with wages, with the highest levels of statistical significance for the full sample and professional occupations.

\section{Conclusions}

Economists have long understood the importance of distinguishing general from specific skills. One particularly promising approach to measuring specific skills at the occupation level is to study the tasks associated with each occupation. We show that task-based measures can be extended and potentially improved by supplementing these measures with information about tool use. Tool use measures allow us to generate a new measure for skill that varies across occupations. Correlation coefficients indicate that tool-use measures are likely to capture features of occupations that differ from task-based proxies for skill. Wage regressions indicate that the number of tools used in an occupation, especially those tools that are specific to an occupation, explain some of the occupational-level variation in wages. For most major occupation groups, the number of job-specific tools, those used by $2 \%$ or fewer of all workers outside of an occupation, are associated with higher paying occupations.

While our work indicates the potential for using detailed information about tools to identify occupationspecific and general skills, it also suggests that tool mastery is only one aspect of a worker's human capital and its relative value will differ with occupational characteristics. The link between tool use and skill requirements might also be affected by the investment policies of firms: When firms use their tools and machines for long periods and workers have to cope with outworn or technically obsolete tools, this might lead to higher skill requirements; workers have to, so to say, complement for the tools' weaknesses. In our regression results, the relationship between tool use and wages differs by occupation type. Sales, service and administrative occupations use few tools and the most valuable human capital is in the mastery of cognitive and abstract tasks. In professional and blue-collar occupations, tool mastery, as measured by the number of job-specific tools used, is likely to be a valuable form of human capital. 


\section{Acknowledgements}

The authors thank Karen Conway, Peter Meyer, Seth Murray, Jay Stewart and 2 anonymous referees for helpful comments.

All views expressed in this paper are those of the authors and do not necessarily reflect the views or policies of the U.S. Bureau of Labor Statistics.

\section{Authors' contributions}

Both authors contributed equally to the project's conception and design, the analysis and interpretation of data, and the drafting and revision of the manuscript. CMC acquired, stored, and maintained the data. Both authors read and approved the final manuscript.

\section{Funding}

Neither author received funding specifically designated to support this research. Robert Mohr thanks the University of Canterbury and University of New Hampshire for supporting this work through, respectively, the Erskine Visiting Scholars program and a summer research grant.

\section{Availability of data}

The datasets analyzed in this study were derived from the following public domain resources: United States Department of Commerce. Bureau of the Census. American Community Survey 2010-2014 5-YEAR PUMS. Ann Arbor, MI: Inter-university Consortium for Political and Social Research [distributor], 201710-20. Persistent URL: https://doi.org/10.3886/E100486V2. O*NET Standard Occupation Classification crosswalk, available at: https://www.onetcenter.org/ crosswalks.html\#soc. O*NET 15.0 Database by the U.S. Department of Labor, Employment and Training Administration (USDOL/ETA). Data available at: https://www.onetcenter.org/db_releases.html. Data are used under the CC BY 4.0 license. USDOL/ETA has not approved, endorsed, or verified the results or conclusions reported here.

\section{Competing interests}

The authors declare that they have no competing interests.

\section{Author details}

1 US Bureau of Labor Statistics, 2 Massachusetts Ave., NE, Washington, DC 20212, USA. ${ }^{2}$ Department of Economics, Paul College of Business and Economics, University of New Hampshire, Durham, NH 03824, USA.

\section{Appendix}

See Table 8 .

Table 8 Number of job-specific tools used, by definition of specificity. Source: $O *$ NET 15.0: T2 supplement

\begin{tabular}{lllrlrl}
\hline $\begin{array}{l}\text { Specificity } \\
\text { definition (\%) }\end{array}$ & \multicolumn{7}{l}{ Number of tools } \\
\cline { 2 - 7 } & $\mathbf{0}$ & $\mathbf{1}$ & $\mathbf{2}$ & $\mathbf{3}$ & $\mathbf{4}$ & $\mathbf{5 +}$ \\
\hline$<.5$ & 19.02 & 13.55 & 11.9 & 6.1 & 7.95 & 41.48 \\
$<1$ & 14.52 & 14.06 & 8.68 & 2.8 & 10.59 & 49.34 \\
$<1.5$ & 10.76 & 14.09 & 9.78 & 2.56 & 4.15 & 58.66 \\
$<2$ & 9.77 & 8.12 & 12.32 & 4.07 & 1.14 & 64.58 \\
$<2.5$ & 8.64 & 6.73 & 13.06 & 2.02 & 2.56 & 66.99 \\
$<3$ & 7.83 & 7.42 & 8.54 & 6.62 & 2.54 & 67.05 \\
$<3.5$ & 7.82 & 6.39 & 6.95 & 2.78 & 3.43 & 72.63 \\
$<4$ & 6.75 & 3.06 & 10.68 & 2.97 & .56 & 75.97 \\
$<4.5$ & 5.83 & 3.42 & 11.04 & 1.64 & 1.89 & 76.17 \\
$<5$ & 5.83 & 3.42 & 5.79 & 6.48 & 1.06 & 77.42
\end{tabular}

Figures show the average number of job-specific tools used per worker, weighted by 2010 ACS employment totals given a varying definitions of jobspecific. Italic values of Row 4 indicates definition used in Tables 5 and 6
Received: 11 September 2018 Accepted: 2 May 2019

Published online: 16 May 2019

\section{References}

Acemoglu, D., Autor, D.H.: Skills, tasks and technologies: implications for employment and earnings. Handb. Labor Econ. 4, 1043-1171 (2011)

Arabsheibani, G.R., Marin, A.: If not computers then what? Returns to computer use in the UK revisited. Appl. Econ. 38(21), 2461-2467 (2006)

Autor, D.H.: The "task approach" to labor markets: an overview. J. Labour Market Res. 46(3), 185-199 (2013)

Autor, D.H., Handel, M.J.: Putting tasks to the test: human capital, job tasks, and wages. J. Labor Econ. 31 (2 Part 2), S59-S96 (2013)

Autor, D.H., Katz, L.F., Krueger, A.B.: Computing inequality: have computers changed the labor market? Q. J. Econ. 113(4), 1169-1213 (1998)

Autor, D.H., Levy, F., Murnane, R.J.: The skill content of recent technological change: an empirical exploration. Q. J. Econ. 118(4), 1279-1333 (2003). https://doi.org/10.1162/003355303322552801

Autor, H., Katz, L., Kearney, M.: Measuring and interpreting trends in economic inequality. Am. Econ. Rev. Pap. Proc. 96(2), 189-194 (2006)

Cunningham, C., Mohr, R.D.: Wage and job skill distributions in the national compensation survey. Mon. Labor Rev. 140, 1 (2017)

Dierdorff, E.C., Drewes, D.W., Norton, J.J.: O* NET tools and technology: a synopsis of data development procedures. North Carolina State University, Raleigh (2006)

Firpo, S., Fortin, N.M., Lemieux, T:: Occupational tasks and changes in the wage structure. IZA Discussion Paper No. 5542 (2011)

Gathmann, C., Schönberg, U.: How general is human capital? A task-based approach. J. Labor Econ. 28(1), 1-49 (2010)

Goos, M., Manning, A.: Lousy and lovely jobs: the rising polarization of work in Britain. Rev. Econ. Stat. 89(1), 118-133 (2007)

Granada Research.: Why coding and classifying products is critical to success in electronic commerce. White Paper. Granada Research. (2001)

Green, F., Felstead, A., Gallie, D., Henseke, G.: Skills and work organisation in Britain: a quarter century of change. J. Labour Market Res. 49(2), 121-132 (2016)

Handel, M.J.: What do people do at work? J. Labour Market Res. 49(2), 177-197 (2016a)

Handel, M.J.: The O*NET content model: strengths and limitations. J. Labour Market Res. 49(2), 157-196 (2016b)

Levenson, A., Zoghi, C.: Occupations, human capital and skills. J. Labor Res. 31(4), 365-386 (2010)

Mane, F., Miravet, D.: Using the job requirements approach and matched employer-employee data to investigate the content of individuals' human capital. J. Labour Market Res. 49(2), 133-155 (2016)

Morissette, R.: Computers, fax machines and wages in Canada: what really matters? Statistics Canada Working Paper (126). (1998)

Pabilonia, S.W., Zoghi, C.: Returning to the returns to computer use. Am. Econ. Rev. 95(2), 314-317 (2005)

Rohrbach-Schmidt, D., Tiemann, M.: Educational (Mis) match and skill utilization in Germany: assessing the role of worker and job characteristics. J. Labour Market Res. 49(2), 99-120 (2016)

Snower, D.J., Goerlich, D: Multitasking and wages. IZA Discussion Paper, No. 7426. (2013)

Spitz-Oener, A.: Technical change, job tasks, and rising educational demands: looking outside the wage structure. J. Labor Econ. 24(2), 235-270 (2006)

Zoghi, C., Pabilonia, S.: Which workers gain upon adopting a computer? Can. J Econ. 40(2), 423-444 (2007)

\section{Publisher's Note}

Springer Nature remains neutral with regard to jurisdictional claims in published maps and institutional affiliations. 